\title{
Modern Look at Transverse Myelitis and Inflammatory Myelopathy
}

\section{Epidemiology of the National Veterans Health Administration Population}

\author{
Justin R. Abbatemarco, MD,* Jonathan R. Galli, MD, * Michael L. Sweeney, MD, Noel G. Carlson, PhD, \\ Verena C. Samara, MD, Haley Davis, MD, Stefanie Rodenbeck, MD, Ka-Ho Wong, BS, MBA, \\ M. Mateo Paz Soldan, MD, PhD, John E. Greenlee, MD, John W. Rose, MD, Alen Delic, MS, and \\ Stacey L. Clardy, MD, PhD
}

Neurol Neuroimmunol Neuroinflamm 2021;8:e1071. doi:10.1212/NXI.0000000000001071

\section{Abstract}

\section{Background and Objectives}

To characterize population-level data associated with transverse myelitis (TM) within the US Veterans Health Administration (VHA).

\section{Methods}

This retrospective review used VHA electronic medical record from 1999 to 2015 . We analyzed prevalence, disease characteristics, modified Rankin Scale (mRS) scores, and mortality data in patients with TM based on the 2002 Diagnostic Criteria.

\section{Results}

We identified 4,084 patients with an International Classification of Diseases (ICD) code consistent with TM and confirmed the diagnosis in 1,001 individuals ( $90.7 \%$ males, median age $64.2,67.7 \%$ Caucasian, and $31.4 \%$ smokers). The point prevalence was 7.86 cases per 100,000 people. Less than half of the cohort underwent a lumbar puncture, whereas only $31.8 \%$ had a final, disease-associated TM diagnosis. The median mRS score at symptom onset was 3 (interquartile range 2-4), which remained unchanged at follow-up, although less than half (43.2\%) of the patients received corticosteroids, IVIg, or plasma exchange. Approximately onequarter of patients $(24.3 \%)$ had longitudinal extensive TM, which was associated with poorer outcomes $(p=0.002)$. A total of 108 patients $(10.8 \%)$ died during our review (94.4\% males, median age $66.5 \%$, and $70.4 \%$ Caucasian). Mortality was associated with a higher mRS score at follow-up (OR 1.94, 95\% CI, 1.57-2.40) and tobacco use (OR 1.87, 95\% CI, 1.17-2.99).

\section{Discussion}

This national TM review highlights the relatively high prevalence of TM in a modern cohort. It also underscores the importance of a precise and thorough workup in this disabling disorder to ensure diagnostic precision and ensure optimal management for patients with TM in the future.

\author{
Correspondence \\ Dr. Clardy \\ stacey.clardy@hsc.utah.edu
}




\section{Glossary}

AQP-4 = aquaporin-4; ICD = International Classification of Diseases; IQR = interquartile range; IVIg = IV immune globulin; LETM = longitudinally extensive TM; MOG = myelin oligodendrocyte; $\mathbf{m R S}=$ modified Rankin Scale; $\mathbf{M S}=$ multiple sclerosis; NMOSD = neuromyelitis optica spectrum disorder; SLE = systemic lupus erythematosus; TM = transverse myelitis; TMCWG = TM Consortium Working Group; VHA = Veterans Health Administration; VistA = VHA Health Information Systems and Technology Architecture.

Transverse myelitis (TM) comprises a heterogeneous group of inflammatory disorders affecting the spinal cord, which can present with a wide range of motor, sensory, and autonomic dysfunction. ${ }^{1}$ Potential mechanisms encompass demyelinating, infectious/parainfectious, autoimmune, and cryptogenic disorders. This broad differential can overlap with noninflammatory myelopathies and can be very challenging for clinicians to navigate, causing delays in diagnosis or treatment. ${ }^{2}$ The lack of longitudinal studies outside of referral centers has also hampered the understanding of this complex disorder. ${ }^{3-5}$

There have been few contemporary studies investigating the prevalence of TM within the United States. One study investigated cases from 1960 to 1990 in New Mexico and found a total of 33 cases with estimated TM incidence rates of 4.6/ $1,000,000$ per year. ${ }^{6} \mathrm{~A}$ more recent study investigating cases within Olmsted County $(\mathrm{MN})$ calculated the prevalence of idiopathic acute TM at 7.9 per 100,000 between 2003 and 2016. ${ }^{5}$ International reports in Israel and United Arab Emirates reported a TM prevalence of $1.34 / 1,000,000$ per year and $0.18 / 100,000$ per year, respectively. ${ }^{7,8}$ All these reports are limited by differing diagnostic criteria and small sample sizes, which are analyzed within relatively homogeneous patient populations.

The objective of this study was to determine point prevalence, clinical characteristics, and mortality associated with TM in the National US Veterans Health Administration (VHA) population. We selected the VHA health care system as it is the largest integrated US health care system and offers a geographically diverse population to study, with a goal to improve awareness of TM to ensure prompt recognition and treatment.

\section{Methods}

\section{Patient Population}

We performed a retrospective review within the US VHA Health Information Systems and Technology Architecture (VistA) from January 1, 1999, to December 30, 2015. This study was approved by the University of Utah institutional review board and the Research and Development committee of the VHA Salt Lake City Health Care System (IRB 00067656). As part of study review, a waiver of informed consent was requested and approved by the IRB.

The study population consisted of all patients seeking care in the VHA system including all inpatient and outpatient VHA visits. We were broadly inclusive to ensure that all TM cases were identified within the VHA system based on International Classification of Diseases (ICD)-9 codes (Figure 1)..$^{5}$ This was followed by a retrospective review of each individual chart to ensure that cases met the definite/possible TM diagnostic criteria outlined by the TM Consortium Working Group (TMCWG) in 2002. ${ }^{1}$ In accordance with the TMCWG diagnostic criteria, we characterized cases as disease-associated TM if the myelitis was determined to be related to a secondary process such granulomatous disease, infection, MS, or other demyelinating disease. After the exclusion of these diseaseassociated myelopathies, a diagnosis of idiopathic TM was made if their clinical symptoms were consistent with spinal cord dysfunction evolving over hours to 21 days. ${ }^{1}$ Patients with an alternative diagnosis, including dural arteriovenous fistula-related myelopathies, were excluded from further analysis. Information on those patients was not available. Each case was cross-checked by medical record number and birth date to avoid duplication of patient records.

\section{Point Prevalence Calculation}

For this VHA population-based study, we included all patients of both sexes and all ages and ethnicities. VistA identified $12,212,061$ unique individuals within the VHA from January 1, 1999, to December 30, 2015; this total was used as the base denominator to determine point prevalence. This total included all unique inpatient and outpatient VHA visits from that time frame. The point prevalence calculation was based on TM cases that were diagnosed during our search period. We applied a conservative model of prevalence and excluded cases of TM not clearly diagnosed during the study period, including those that had been historically diagnosed. This accounts for the discrepancy in total TM cases identified within the study compared with the number used for the final point prevalence calculation. Those individuals excluded from the prevalence calculation were included in all additional analyses. Incidence rates were not calculated as the exact time of TM diagnosis was not always definitively known or reported and therefore would result in biased incidence estimates during this time period.

\section{Clinical Follow-up and Outcome Measures}

From the medical record, we abstracted information informing race/ethnicity, age, sex, along with date of diagnosis, smoking status (binary value of smoking vs nonsmoker), antecedent trigger, and mortality data for all patients with TM. The time/delay to diagnosis was not consistently available in our data set, so this was not included in the analysis. The mortality data and cause of death were compiled 


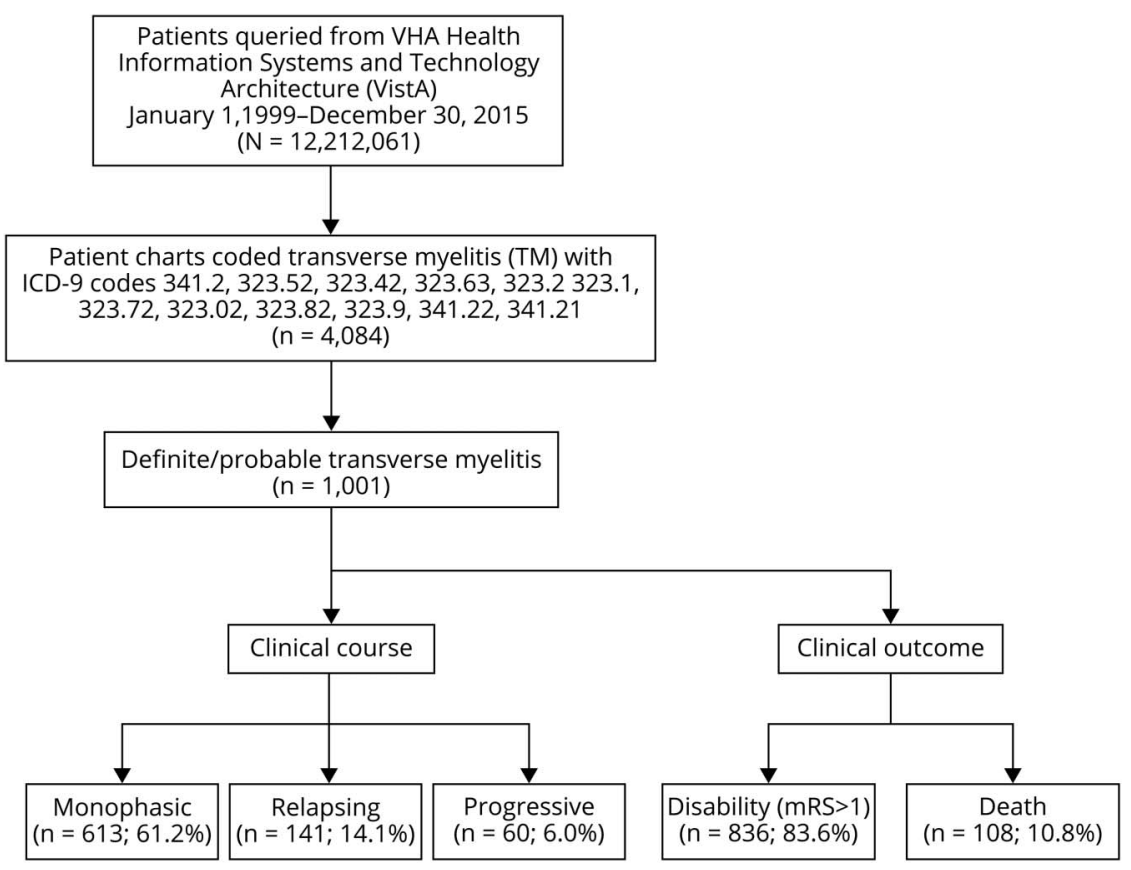

from the VHA National Patient Care Database and confirmed using the Beneficiary Identification and Record Locator Subsystem. Limited details around the cause of death were included, but no further details were available for review and therefore not reported.

Laboratory values including aquaporin-4 (AQP-4) and myelin oligodendrocyte (MOG) IgG autoantibodies were not included in this analysis, as commercial testing was not available during our entire search period. CSF analysis including unique CSF oligoclonal bands was included when available. Detailed serologic and CSF test results, including infectious studies, were not routinely available and are not reported in this study. MRI data were based solely on radiology reports. Longitudinally extensive TM (LETM) was defined as an intramedullary lesion extending over 3 or more vertebral segments on a spinal cord MRI. Further radiographic descriptors were not reported in this study. MRI brain findings were registered as normal or abnormal; this binary classification registered age-related changes including microvascular changes as normal.

Corticosteroids, IV immune globulin (IVIg), or plasma exchange were defined as first-line therapies. The treatment was defined as acute if it was given during the index admission or office visit. Therapeutic response was based either on clinicianor patient-reported outcomes and characterized as improved, no improvement with stable symptoms, or worsening of symptoms. In addition, the modified Rankin Scale (mRS) score was calculated at diagnosis and at the last follow-up based on available information in the chart. Because the medical records did not consistently document other validated or uniform outcome measures and varied extensively in detail, we were unable to report on outcomes beyond these simple descriptors.

\section{Statistical Analysis}

Patient demographics, medical history, and MRI features were summarized with descriptive statistics. Qualitative variables were shown as absolute frequencies and percentages. Continuous variables were shown with mean and SD. Multivariate logistic regression models were built to show significant associations of risk factors and/or predictors with mortality. Covariates were added to the model a priori, and significance was set at $p<0.05$. Multivariate ordinal and logistic regression were performed in the subgroup of patients who had CSF performed to assess possible associations with the patients' reported $\mathrm{mRS}$ score and presence of LETM. OR and 95\% CIs were reported. All data analyses were performed using STATA version 16.1 (Stata Corp; College Station, TX).

\section{Data Availability}

The corresponding author is in possession of detailed methods and anonymized data of the present study, which is available on reasonable request.

\section{Results}

\section{Point Prevalence}

We identified 961 patients who were diagnosed with TM from January 1, 1999, to December 30, 2015. This equated to a point prevalence of $961 / 12,212,061$, which was equivalent to 7.86 cases per 100,000 people. This included all patients with TM including disease-associated and idiopathic TM cases. 
Table 1 Etiology and Outcomes of the TM Cohort

\begin{tabular}{|c|c|c|c|c|}
\hline & $\begin{array}{l}\text { Entire TM } \\
\text { cohort } \\
(N=1,001)\end{array}$ & $\begin{array}{l}\text { Non-LETM } \\
\text { cohort } \\
(\mathrm{n}=757)\end{array}$ & $\begin{array}{l}\text { LETM } \\
\text { cohort } \\
(n=244)\end{array}$ & $\begin{array}{l}p \\
\text { Value }\end{array}$ \\
\hline $\begin{array}{l}\text { Acute disseminated } \\
\text { encephalomyelitis }\end{array}$ & $20(2.0 \%)$ & $16(2.1 \%)$ & $4(1.7 \%)$ & 0.44 \\
\hline $\begin{array}{l}\text { Infection/ } \\
\text { parainfectious } \\
\text { process }\end{array}$ & $48(4.8 \%)$ & $34(4.5 \%)$ & $14(5.8 \%)$ & 0.026 \\
\hline Multiple sclerosis & $164(16.4 \%)$ & $123(16.2 \%)$ & $41(17.0 \%)$ & 0.45 \\
\hline $\begin{array}{l}\text { Neuromyelitis } \\
\text { optica spectrum } \\
\text { disorder }\end{array}$ & $31(3.1 \%)$ & $11(1.5 \%)$ & $20(8.3 \%)$ & $<0.001$ \\
\hline Paraneoplastic & $5(0.5 \%)$ & $3(0.4 \%)$ & $2(0.8 \%)$ & 0.35 \\
\hline Sarcoidosis & $11(1.1 \%)$ & $1(0.1 \%)$ & $10(4.1 \%)$ & $<0.001$ \\
\hline Sjogren & $4(0.4 \%)$ & $2(0.3 \%)$ & $2(0.8 \%)$ & 0.25 \\
\hline $\begin{array}{l}\text { Systemic lupus } \\
\text { erythematosus }\end{array}$ & $9(0.9 \%)$ & $7(0.9 \%)$ & $2(0.8 \%)$ & 0.62 \\
\hline Idiopathic & $682(68.2 \%)$ & $543(71.7 \%)$ & $139(57.4 \%)$ & $<0.001$ \\
\hline Other & $27(2.7)$ & $17(2.3 \%)$ & $10(4.1 \%)$ & 0.10 \\
\hline $\begin{array}{l}\text { mRS score at last } \\
\text { visit }\end{array}$ & & & & 0.002 \\
\hline 0 & $19(1.9 \%)$ & $16(2.1 \%)$ & $3(1.2 \%)$ & \\
\hline 1 & $156(15.6 \%)$ & $133(17.6)$ & $23(9.4 \%)$ & \\
\hline 2 & $238(23.8 \%)$ & $172(22.9 \%)$ & 65 (26.6\%) & \\
\hline 3 & 189 (18.9\%) & $138(18.2 \%)$ & $51(20.9 \%)$ & \\
\hline 4 & $220(22.0 \%)$ & $153(20.2 \%)$ & 67 (27.5\%) & \\
\hline 5 & 33 (3.3\%) & 19 (2.5\%) & 14 (5.7\%) & \\
\hline
\end{tabular}

Abbreviations: LETM = longitudinal extensive transverse myelitis; $\mathrm{mRS}=$ modified Rankin Scale; TM = transverse myelitis.

\section{Demographics}

A total of 4,084 patients were identified with an ICD-9 code for TM, and the diagnosis was confirmed in 1,001 individuals based on our study criteria (Figure 1). The discrepancy between the cases used in the point prevalence calculation and total cases was due to the fact that some patients were identified with TM ICD code, yet their diagnosis was made before January 1, 1999. The population was predominately Caucasian (67.8\%), whereas 18.3\% were African American, 3.1\% Hispanic/Latino, and 2.0\% Pacific Islander/Asian. The remainder of the demographics were similar to other VHA cohorts with a predominance of older male $(90.7 \%)$ with a median age of 64.2 years (interquartile range [IQR $] 53.5-69.9$ years). Approximately one-third of the cohort $(31.5 \%)$ were smokers.

\section{Clinical and MRI Features}

Patients with TM presented with moderate to severe deficits at the time of diagnosis (median mRS score 3 [IQR 2-4]). The majority of intramedullary spinal cord lesions were
Table 2 CSF Results

\begin{tabular}{llll}
\hline CSF data $(\mathbf{n}=\mathbf{4 2 4})$ & Mean (SD) & Median (IQR) & Range \\
\hline White blood cells (cells/mL) & $22.2(86.0)$ & $3(1-12)$ & $0-960$ \\
\hline Red blood cells (cells/mL) & $260.4(2,243.9)$ & $3(0-20)$ & $0-36,000$ \\
\hline Protein $(\mathbf{m g} / \mathbf{d L})$ & $69.3(68.5)$ & $57(39-75)$ & $16-709$ \\
\hline Glucose $(\mathbf{m g} / \mathbf{d L})$ & $72.4(25.8)$ & $65(58-79)$ & $18-204$ \\
\hline
\end{tabular}

located within the thoracic spinal cord (42.6\%). Cervical and lumbar cord lesions accounted for $35.5 \%$ and $4.2 \%$ of the lesions, respectively. The remaining TM attacks spanned both the cervical and thoracic regions. Approximately one-quarter of patients $(24.3 \%)$ had LETM. A total of 715 patients had MRI brain radiology reports available; of these, 172 (17.2\%) were reportedly abnormal.

Approximately $68.2 \%$ of cases were diagnosed as idiopathic TM (Table 1). Among all TM cases, the most common antecedent event was a prodromal infection $(9.7 \%)$ or vaccination (3.3\%). MS was the most frequent final diagnosis (total 164 cases [16.7\%]). Of those patients with an abnormal MRI brain, 87 (50.6\%) were eventually diagnosed with multiple sclerosis (MS). Similar results were found within the LETM cohort (Table 1).

\section{CSF Analysis}

CSF was available in 424 patients (42.4\%; Table 2). An elevated protein was found in $68.4 \%$ of cases (median $57 \mathrm{mg} / \mathrm{dL}$; IQR [39-75]; reference range $>50 \mathrm{mg} / \mathrm{dL}$ ), whereas 221 patients $(52.1 \%)$ had an elevated white blood cell count (median 3 white blood cells; IQR [1-12]; reference range $>5$ white blood cells $/ \mathrm{mL}$ ). Unique CSF oligoclonal bands (reference $\geq 2$ unique bands) were found in 109 patients $(25.6 \%)$, and $59(54.1 \%)$ of those patients had a final diagnosis of MS. A total of 35 patients with LETM (36\%) had oligoclonal bands.

In our logistic model, a CSF pleocytosis was significantly associated with increased odds of LETM (OR $=1.01,95 \%$ CI [1.001-1.018]), whereas oligoclonal bands were marginally associated with a decrease in odds of LETM $(\mathrm{OR}=0.57,95 \%$ CI $[0.32-1.01])$. Elevated protein $(\mathrm{OR}=1.01,95 \% \mathrm{CI}$ $[1.002-1.012])$ and elevated glucose $(\mathrm{OR}=1.01,95 \% \mathrm{CI}$ [1.002-1.023]) were associated with worsening mRS score outcomes.

\section{Clinical Outcomes and Treatment}

Average length of follow-up within the VHA system was 12.5 years (95\% CI: 11.7-13.3 years), which included both inpatient and outpatient visits. The median $\mathrm{mRS}$ score at follow-up remained unchanged at 3 (IQR 2-4). A total of $41.3 \%$ of the cohort had an mRS score of less than 3 . When analyzing the LETM cohort, only $37.2 \%$ of the cohort had an $\mathrm{mRS}$ score of less than 3 . Acute treatment was initiated in 
Table 3 Acute Treatments for the TM Cohort

\begin{tabular}{ll}
\hline Acute treatment & Frequency (\%) \\
\hline Corticosteroids & $368(36.8)$ \\
\hline Corticosteroids and IVIg & $24(2.4)$ \\
\hline Corticosteroids and PLEX & $40(4.0)$ \\
\hline PLEX & $9(0.9)$ \\
\hline IVIg & $13(1.3)$ \\
\hline Other & $33(3.3)$ \\
\hline None & $126(12.6)$ \\
\hline Unknown & $388(38.8)$ \\
\hline
\end{tabular}

Abbreviations: IVIg = IV immune globulin; PLEX = plasma exchange; $\mathrm{TM}=$ transverse myelitis.

43.2\% of the cohort, with corticosteroids as the most common treatment (Table 3). Plasma exchange was initiated in $4.9 \%$ of the cohort. Based on clinical records, patients and/or clinicians denoted that approximately $71.7 \%$ of patients who received first-line immunotherapies (corticosteroids, IVIg, or plasma exchange) had some improvement in functional outcomes, and $22.6 \%$ remained stable. The majority of patients remained off long-term immunotherapies, but $12.0 \%$ were continued on prednisone beyond the acute treatment period.

\section{Mortality}

A total of 108 patients (10.8\%) died during our 15-year search period ( $94.4 \%$ males, median age 66.5 years [IQR 62.3-77.2 years], and $70.4 \%$ Caucasian). The most common cause of death was related to malignancy (20\%), comorbidities (16.8\%), or TM complications (9.5\%). The median survival time was 8.9 years (range 4.3-16.2 years) from diagnosis. In our logistical model (Figure 2), increases in mortality were associated with age (OR 1.06 [1.04-1.08], $p<0.001$ ), mRS score at follow-up (OR 1.94, 95\% CI 1.57-2.40), and tobacco use (OR 1.87, 95\% CI 1.17-2.99). There was no association with sex $(p=0.75)$ or race $(p=0.90)$.

\section{Discussion}

This modern investigation into TM point prevalence encompassing the US population revealed 7.86 TM cases per 100,000 people which was higher than previously reported ${ }^{6,7}$ though similar to the most recent county based study in the United States. ${ }^{5}$ Our findings highlighted the limited diagnostic evaluation pursued at the time of diagnosis. Over half (57.6\%) of cases lacked CSF testing, which is a core part of the TMCWG $^{1}$ diagnostic criteria and offers important diagnostic and prognostic information for patients and clinicians alike. Moreover, only one-third (31.8\%) of cases were assigned a more precise final diagnosis other than TM, which is much lower than should be achievable. ${ }^{3}$ Our findings emphasize the need for a precise and comprehensive evaluation to ensure optimal management for patients with TM in the future.

Our national US point prevalence estimate is one of the highest reported to date and provides a contemporary understanding of TM across a diverse population. Our use of the VHA database allowed us to account for the fragmentation of the private US health care system, as previous studies focused on state/county level data, which limits their generalizability. ${ }^{5,6,9}$ Our rigorous approach to identify all cases over a 15 -year search (with physician record review of all cases) minimized undercounting within limited observation periods. Other factors that may have contributed to this higher point prevalence include the evolution of diagnostic criteria, and more widely available technology, such as MRI. Geographic variability in the prevalence of TM that has not been previously reported, but has been seen in other neuroimmunologic conditions such as neuromyelitis optica spectrum disorder (NMOSD), ${ }^{10}$ could also account for some discrepancy in regional estimates. ${ }^{11} \mathrm{~A}$ frequently cited prior study between 1955 and 1975 in Israel found an incidence of 1.34 per 1,000,000 but only included 63 TM cases using different inclusion criteria. ${ }^{7}$ A more recent, single-center study using the TMCWG criteria ${ }^{1}$ examined 60 patients with TM between 2001 and 2005 in New Zealand and found an incidence rate for idiopathic acute TM of 6.3 per $1,000,000 .{ }^{12}$ The most recent TM study was conducted in Olmsted County and calculated the prevalence of idiopathic TM at 7.9 per 100,000 between 2003 and $2016 .{ }^{5}$ Our point prevalence calculation included all TM cases including those with a disease-associated classification. We specifically included all cases of TM in our calculation to provide a real-world calculation for the frequency of TM. It should be noted that our lower prevalence calculation when compared with Olmsted County may be related to incomplete clinical data; that study team ${ }^{5}$ likely had access to more complete records given their smaller study population along with their unique records linkage system.

Although we identified 4,084 patients with an ICD code for $\mathrm{TM}$, we confirmed the diagnosis in less than one-quarter of those cases. This may reflect, in part, clinician confusion concerning TM as an actual disease entity. ${ }^{3,4,13}$ The TM label is often used by clinicians to describe a myelopathic disease processes without clear evidence of inflammation. Less than $45 \%$ of cases in our cohort had CSF results available. This may be an underestimate as some patients had testing outside of the VHA, but that is still a considerable number of patients lacking a proper evaluation, which is standard of care. ${ }^{1} \mathrm{~A}$ study by Barreras et al. analyzed cases within a tertiary myelopathy referral center and found that only 54\% of TM referrals had documented inflammatory changes. The remainder of the cases showed a variety of different pathologies, including cases requiring surgical intervention. Similar results have been in other recent cohorts. ${ }^{3}$ All these factors may delay the proper diagnosis and treatment. Hence, it is critical to use the diagnostic nomenclature correctly. ${ }^{13}$ Both the nomenclature 


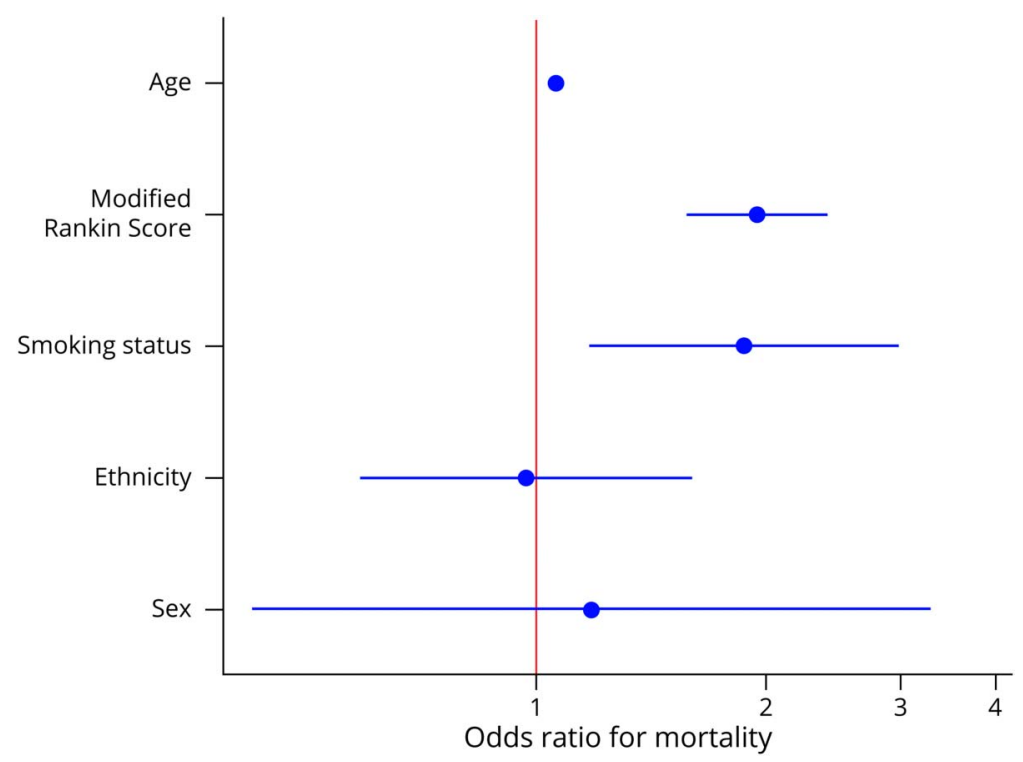

Model fit to mortality. Adjusted for age, mRS score, smoking status, ethnicity, and sex. mRS = modified Rankin Scale. (e.g., use of the term myelitis vs myelopathy) and the diagnostic criteria would benefit from a consensus update.

TM is classically described with subacute, symmetric symptoms at onset, with a well-defined truncal sensory level, ${ }^{11}$ yet we now recognize that TM and other inflammatory myelopathies can present in a myriad of ways including sudden, asymmetric symptoms without a clear sensory level. ${ }^{4}$ A careful clinical history with particular attention to the onset of symptoms can be central in determining the underlying etiology of a myelopathy. ${ }^{4,14}$ For example, rapid development of severe deficits (i.e., paraplegia or quadriplegia) within 12 hours along with a noninflammatory CSF profile should cue clinicians to a possible spinal cord infarct. ${ }^{3,15}$ This is especially true in older patients with vascular risk factors as was seen in our cohort. A more chronic evolution in symptoms can be suggestive of a vascular lesion such as a dural arteriovenous fistula or a structural lesion such as a spondylotic myelopathy. Clinical history can be paired with radiographic findings to determine the exact etiology. For example, the lesion distribution on axial imaging has been shown to be very informative. MS lesions typically involve peripheral, myelinated tracts, whereas spinal cord infarct will follow discrete vascular distribution. Detailed clinical and radiographic information is beyond the scope of this article but has been previously described and available within the following references. ${ }^{16,17}$

The TMCWG classified TM into idiopathic TM and diseaseassociated TM. Disease-associated TM consists of cases associated with a secondary cause such as demyelinating disorders (MS and NMOSD), systemic rheumatic diseases (Sjogren syndrome and systemic lupus erythematosus [SLE]), or infections (syphilis, Lyme disease, and HIV). The idiopathic TM label should only apply to those cases where a comprehensive evaluation is unrevealing. ${ }^{1}$

Recent advances, including the discovery of autoantibodies such as AQP-4 and MOG IgG, have offered greater clarity regarding potential etiologies of TM. ${ }^{5}$ Our search period from 1999 to 2015, in part, predates the discovery and widespread availability of these assays, and not all VA centers had consistent access to those tests. For these reasons, we were unable to include them in this analysis. In addition, the diagnostic criteria for NMOSD similarly evolved during this time, limiting the conclusions we could draw from our findings. Within our cohort, $1.5 \%$ of patients were diagnosed with TM related to a systemic rheumatic disease, which increased to $1.7 \%$ when analyzing only the LETM patients. NMOSD had a more dramatic increase from $3.1 \%$ to $8.3 \%$ within those respective subgroups. Recent data have illustrated that patients previously diagnosed with a systemic rheumatic disorders such as SLE often also have coexisting, pathologically relevant AQP-4 antibodies. ${ }^{18}$ Our data regarding the rates of MS were consistent with previous reports. ${ }^{19,20}$ Although the diagnostic criteria for this disorder have also evolved with time, MS is a widely recognized disorder among neurologists and general practitioners alike, and our findings likely reflect that fact. We identified a little over $16 \%$ of TM cases that eventually went on to be diagnosed with MS, which is similar to previous reported hospital-based series. ${ }^{5,19}$ The majority of our MS cases had an abnormal MRI brain or unique oligoclonal bands in the CSF.

Various infectious agents have been described in association with TM, although a specific pathogen is rarely identified. Limited infectious markers were available in our study, which 
is a significant limitation, especially as military deployment could have exposed our population to a variety of infectious agents. Clinicians identified infectious/parainfectious processes in less than $10 \%$ of TM cases, whereas in the literature, $30 \%-60 \%$ of TM cases were espoused to an antecedent illness. ${ }^{6,21,22}$ As mentioned before, these are older studies (published before 1990), making direct comparison difficult. Clinicians should ensure that a complete travel history is completed in all patients with myelitis along with a focus on potential exposures, which might raise the risk of an infectious myelopathy. $^{23}$

Concerns around vaccines as a trigger for TM have existed for many years, although it was a relatively rare association in our study. ${ }^{24}$ In a metanalysis that examined TM associated with vaccinations between 1970 and 2009, 37 cases of TM were reported to be associated with various vaccines, with the vast majority of cases (73\%) occurring within the first month postvaccination. The most common vaccination associated with TM in that analysis was against the hepatitis B virus. ${ }^{25} \mathrm{~A}$ more recent study from 2007 to 2012 found only 7 TM cases among 64 million vaccine doses. ${ }^{24}$ These relatively low rates are consistent with our results showing antecedent vaccination in $3.3 \%$ of our cases.

TM has the potential to cause substantial disability. In our series, $21.4 \%$ of patients were unable to ambulate unassisted at their follow-up visit ( $\mathrm{mRS}$ score $\geq 4$ ). Studies published before the TMCWG guidelines reported that up to one-third of patients with TM remained unable to ambulate with mortality ranging from $5 \%$ to $10 \% .{ }^{7,21,26}$ More recent studies report severe disability ( $\mathrm{mRS}$ score $\geq 3$ ) ranging from $24.7 \%$ to $35.8 \% .{ }^{19,27}$ In our series, $44.8 \%$ of patients had mRS score $\geq 3$. LETM has been associated with a poorer prognosis in patients with acute TM along with increased rates of relapses. ${ }^{28,29} \mathrm{In}$ our series, patients with LETM had worse outcomes as measured by the mRS $(p=0.002)$.

Most patients with TM do experience some degree of spontaneous recovery in neurologic function, but high-dose corticosteroids are usually employed as an empiric treatment in $\mathrm{TM}$, which was consistent with the results in our cohort. ${ }^{11,19}$ Our study did not identify many cases where additional therapies were used beyond corticosteroids. In particular, there is strong, Class I evidence to support the use of plasma exchange in refractory demyelinating myelitis cases, especially in patients with NMOSD. ${ }^{30-32}$ Rapid immunotherapy initiation along with escalation in treatment in select cases is imperative in optimizing outcomes in this potentially devastating condition. Though not within the scope of our project, neurorehabilitation services should also be an integral part of myelitis treatment. Mortality data are not commonly reported in these more recent cohorts. Our mortality rate of $10.1 \%$ may reflect differences in the methodological aspects of previous studies (collaborative multicenter studies vs hospital-based series).
The strengths of this study included its large sample size using a national health system that ensures equal access to care for all members while accounting for the complexity of the current national health care system. Furthermore, prevalence estimates were calculated across the United States without state-based restriction. There are several important limitations that should be mentioned, including the retrospective data collection, which can introduce unintended bias. The variability of initial and subsequent diagnostic evaluation as guided by the evaluating physicians is also a significant limitation. In addition, some veterans may have sought medical care outside of the VHA system. This includes neuroimaging performed outside of VHA with a variety of scanners and protocols used, which limits interpretation of some of the radiographic findings. A previous investigation found that approximately one-third of veterans reported dual-use primary care (VHA and non-VHA clinicians). ${ }^{33}$ It is unknown whether such patients may have preferentially sought care for TM at non-VHA facilities, but the possibility cannot be excluded. Furthermore, restricting our population to the VHA means that there is an overrepresentation of older, Caucasian men with multiple comorbidities, which limits the generalizability of the results. ${ }^{34}$

By analyzing such a broad group, this study may not reflect important differences among specific TM etiologies including MS, NMOSD, sarcoidosis myelopathy, and other related conditions. As mentioned previously, updates in diagnostic criteria may have influenced national trends in diagnoses among VHA clinicians. In addition, our study was not designed to evaluate the efficacy of immunotherapy in this setting but should be investigated in the future.

This national cohort analysis provides a point prevalence of $\mathrm{TM}$, and underscores that the diagnosis of TM and myelopathy continues to present a significant diagnostic challenge, as the list of possible diagnoses and mimics is extensive. This necessitates a thorough diagnostic workup with consideration of inflammatory and noninflammatory etiologies. Identification of a clear etiology is of paramount importance, given the potential for intervention and prevention of further injury in recurrent inflammatory disease.

\section{Acknowledgment}

This material is the result of work supported with resources and the use of facilities at the George E. Wahlen Veterans Affairs Hospital in Salt Lake City, UT. The contents of this article do not represent the views of VA or the US Government. The authors thank the veterans who have served in the US military and who continue to serve by supporting the advancement of their understanding of neuroimmunologic disease. The Autoimmune Neurology Fellowship training of Drs. Jonathan Galli and Michael Sweeney, and their contributions to this project, was generously supported by the Siegel Rare Neuroimmune Association. 


\section{Study Funding}

No targeted funding reported.

\section{Disclosure}

J.R. Galli and M.L. Sweeney were supported during their fellowship training by a grant from the Siegel Rare Neuroimmune Foundation (SRNA) in support of the work in this manuscript. J.R. Abbatemarco, V.C. Samara, S.J. Rodenbeck, K.H. Wong, J.W. Rose, A. Delic and N. Carlson declare no disclosures relevant to the manuscript. M.L. Sweeney: speaking fees from Genentech. M. Paz Soldan serves on the editorial board for Journal of Neuroimaging and has received research funding from the Western Institute for Veterans Research, the National Multiple Sclerosis Society, the NIH, Biogen, and Novartis. J.E. Greenlee receives honoraria as Associate Editor for MedLink and as chapter editor for the Merck Manual; he has received payment as expert legal witness. S.L. Clardy serves as the Editor of the Neurology Podcast and Neurology Minute and recevies research and/or clinical fellowship support from the Western Institute for Veterans Research, the SRNA, the IDF, Alexion, the Barbara Gural Steinmetz Foundation, and the Sumaira Foundation for NMO; She has performed work on consulting/ advisory boards for Alexion, Genentech, VielaBio, Guidepoint, Clarion Healthcare Consulting, and ExpertConnect, with the majority fees paid to University of Utah Development account. Go to Neurology.org/NN for full disclosures.

\section{Publication History}

Received by Neurology: Neuroimmunology \& Neuroinflammation April 6, 2021. Accepted in final form July 22, 2021.

\section{Appendix Authors}

\begin{tabular}{lll}
\hline Name & Location & Contribution \\
\hline $\begin{array}{ll}\text { Justin R. } \\
\text { Abbatemarco, }\end{array}$ & University of Utah & $\begin{array}{l}\text { Designed and } \\
\text { conceptualized the study; } \\
\text { MD }\end{array}$ \\
& $\begin{array}{l}\text { analyzed the data; and } \\
\text { drafted the manuscript for } \\
\text { intellectual content }\end{array}$ \\
\hline
\end{tabular}

Jonathan R. University of Utah \& George Major role in the Galli, MD E. Wahlen Veterans Affairs acquisition of data; Medical Center designed and conceptualized the study; analyzed the data; and drafted the manuscript for intellectual content

\begin{tabular}{lll}
\hline Michael L. & $\begin{array}{l}\text { Norton Children's Medical } \\
\text { Gweeney, MD } \\
\text { Goup, University of } \\
\text { Leuisville School of }\end{array}$ & $\begin{array}{l}\text { Major role in the acquisition } \\
\text { of data; designed and } \\
\text { conceptualized the study; } \\
\text { analyzed the data; and } \\
\text { drafted the manuscript for } \\
\text { intellectual content }\end{array}$ \\
\end{tabular}

\begin{tabular}{lll}
\hline $\begin{array}{l}\text { Noel G. } \\
\text { Carlson, PhD }\end{array}$ & $\begin{array}{l}\text { Department of Pathology, } \\
\text { Duke University Hospital, } \\
\text { Durham }\end{array}$ & $\begin{array}{l}\text { Interpreted the data and } \\
\text { revised the manuscript for } \\
\text { intellectual content }\end{array}$ \\
\hline Verena C. & $\begin{array}{l}\text { PeaceHealth Neurology, } \\
\text { Springfield, OR, USA }\end{array}$ & $\begin{array}{l}\text { Major role in the acquisition } \\
\text { of data; designed and } \\
\text { conceptualized the study; } \\
\text { analyzed the data; and } \\
\text { drafted the manuscript for } \\
\text { intellectual content }\end{array}$ \\
\end{tabular}

Appendix (continued)

\begin{tabular}{lll}
\hline Name & Location & Contribution \\
\hline $\begin{array}{ll}\text { Haley Davis, } \\
\text { MD }\end{array}$ & $\begin{array}{l}\text { University of Utah \& George } \\
\text { E. Wahlen Veterans Affairs } \\
\text { Medical Center }\end{array}$ & $\begin{array}{l}\text { Major role in the acquisition } \\
\text { of data; designed and } \\
\text { conceptualized the study; } \\
\text { analyzed the data; and } \\
\text { drafted the manuscript for } \\
\text { intellectual content }\end{array}$ \\
\end{tabular}

\begin{tabular}{|c|c|c|}
\hline $\begin{array}{l}\text { Stefanie J. } \\
\text { Rodenbeck, } \\
\text { MD }\end{array}$ & University of Utah & $\begin{array}{l}\text { Interpreted the data and } \\
\text { revised the manuscript for } \\
\text { intellectual content }\end{array}$ \\
\hline $\begin{array}{l}\text { Ka-Ho Wong, } \\
\text { BS, MBA }\end{array}$ & University of Utah & $\begin{array}{l}\text { Interpreted the data and } \\
\text { revised the manuscript for } \\
\text { intellectual content }\end{array}$ \\
\hline
\end{tabular}

\begin{tabular}{|c|c|c|}
\hline $\begin{array}{l}\text { M. Mateo Paz } \\
\text { Soldan, MD, } \\
\text { PhD }\end{array}$ & $\begin{array}{l}\text { University of Utah \& George } \\
\text { E. Wahlen Veterans Affairs } \\
\text { Medical Center }\end{array}$ & $\begin{array}{l}\text { Designed and } \\
\text { conceptualized the study, } \\
\text { interpreted the data; and } \\
\text { revised the manuscript for } \\
\text { intellectual content }\end{array}$ \\
\hline
\end{tabular}

\begin{tabular}{lll}
\hline $\begin{array}{l}\text { John E. } \\
\text { Greenlee, MD }\end{array}$ & $\begin{array}{l}\text { University of Utah \& George } \\
\text { E. Wahlen Veterans Affairs } \\
\text { Medical Center }\end{array}$ & $\begin{array}{l}\text { Interpreted the data and } \\
\text { revised the manuscript for } \\
\text { intellectual content }\end{array}$ \\
$\begin{array}{lll}\text { John W. Rose, } \\
\text { MD }\end{array}$ & $\begin{array}{l}\text { University of Utah \& George } \\
\text { E. Wahlen Veterans Affairs } \\
\text { Medical Center }\end{array}$ & $\begin{array}{l}\text { Interpreted the data and } \\
\text { revised the manuscript for } \\
\text { intellectual content }\end{array}$ \\
\hline $\begin{array}{l}\text { Alen Delic, MS } \\
\text { University of Utah \& George } \\
\text { E. Wahlen Veterans Affairs } \\
\text { Medical Center }\end{array}$ & $\begin{array}{l}\text { Conducted the statistical } \\
\text { analysis and revised the } \\
\text { manuscript for intellectual } \\
\text { content }\end{array}$ \\
$\begin{array}{l}\text { Stacey L. } \\
\text { Clardy, MD, } \\
\text { PhD }\end{array}$ & $\begin{array}{l}\text { University of Utah \& George } \\
\text { E. Wahlen Veterans Affairs } \\
\text { Medical Center }\end{array}$ & $\begin{array}{l}\text { Major role in the acquisition } \\
\text { of data; designed and } \\
\text { conceptualized the study; } \\
\text { analyzed the data; and } \\
\text { drafted the manuscript for } \\
\text { intellectual content }\end{array}$ \\
& &
\end{tabular}

\section{References}

1. Transverse Myelitis Consortium Working Group. Proposed diagnostic criteria and nosology of acute transverse myelitis. Neurology. 2002;59(4):499-505.

2. Beh SC, Greenberg BM, Frohman T, Frohman EM. Transverse myelitis. Neurol Clin. 2013;31(1):79-138.

3. Zalewski NL, Flanagan EP, Keegan BM. Evaluation of idiopathic transverse myelitis revealing specific myelopathy diagnoses. Neurology. 2018;90(2):e96-e102.

4. Barreras P, Fitzgerald KC, Mealy MA, et al. Clinical biomarkers differentiate myelitis from vascular and other causes of myelopathy. Neurology. 2018;90(1):e12-e21.

5. Sechi E, Shosha E, Williams JP, et al. Aquaporin-4 and MOG autoantibody discovery in idiopathic transverse myelitis epidemiology. Neurology. 2019;93(4) e414-e420.

6. Jeffery DR, Mandler RN, Davis LE. Transverse myelitis. Retrospective analysis of 33 cases, with differentiation of cases associated with multiple sclerosis and parainfectious events. Arch Neurol. 1993;50(5):532-535.

7. Berman M, Feldman S, Alter M, Zilber N, Kahana E. Acute transverse myelitis: incidence and etiologic considerations. Neurology. 1981;31(8):966-971.

8. Holroyd KB, Aziz F, Szolics M, Alsaadi T, Levy M, Schiess N. Prevalence and characteristics of transverse myelitis and neuromyelitis optica spectrum disorders in the United Arab Emirates: a multicenter, retrospective study. Clin Exp Neuroimmunol. 2018;9(3):155-161.

9. Klein NP, Ray P, Carpenter D, et al. Rates of autoimmune diseases in Kaiser Permanente for use in vaccine adverse event safety studies. Vaccine. 2010;28(4) 1062-1068.

10. Papp V, Magyari M, Aktas O, et al. Worldwide incidence and prevalence of neuromyelitis optica: a systematic review. Neurology. 2021;96(2):59-77.

11. Frohman EM, Wingerchuk DM. Clinical practice. Transverse myelitis. N Engl J Med. 2010;363(6):564-572.

12. Young J, Quinn S, Hurrell M, Taylor B. Clinically isolated acute transverse myelitis: prognostic features and incidence. Mult Scler. 2009;15(11):1295-1302.

13. Blackburn KM, Greenberg BM. Revisiting transverse myelitis: moving toward a new nomenclature. Front Neurol. 2020;11:519468.

14. Scott TF, Frohman EM, De Seze J, Gronseth GS, Weinshenker BG. Evidence-based guideline: clinical evaluation and treatment of transverse myelitis: report of the 
Therapeutics and Technology Assessment Subcommittee of the American Academy of Neurology. Neurology. 2011;77(24):2128-2134.

15. Zalewski NL, Rabinstein AA, Krecke KN, et al. Characteristics of spontaneous spinal cord infarction and proposed diagnostic criteria. JAMA Neurol. 2019;76(1):56-63.

16. Lopez Chiriboga S, Flanagan EP. Myelitis and other autoimmune myelopathies. Continuum (Minneap Minn). 2021;27(1):62-92.

17. Hardy TA. Spinal cord anatomy and localization. Continuum (Minneap MN). 2021 27(1):12-29.

18. Pittock SJ, Lennon VA, de Seze J, et al. Neuromyelitis optica and non organ-specific autoimmunity. Arch Neurol. 2008;65(1):78-83.

19. Cobo Calvo A, Mane Martinez MA, Alentorn-Palau A, Bruna Escuer J, Romero Pinel L, Martinez-Yelamos S. Idiopathic acute transverse myelitis: outcome and conversion to multiple sclerosis in a large series. BMC Neurol. 2013;13:135.

20. Bruna J, Martínez-Yélamos S, Martínez-Yélamos A, Rubio F, Arbizu T. Idiopathic acute transverse myelitis: a clinical study and prognostic markers in 45 cases. Mult Scler. 2006;12(2):169-173.

21. Christensen PB, Wermuth L, Hinge HH, Bømers K. Clinical course and long-term prognosis of acute transverse myelopathy. Acta Neurol Scand. 1990;81(5):431-435.

22. Lipton HL, Teasdall RD. Acute transverse myelopathy in adults. A follow-up study. Arch Neurol. 1973;28(4):252-257.

23. Toledano M. Infectious myelopathies. Continuum (Minneap MN). 2021;27(1): 93-120.

24. Baxter R, Lewis E, Goddard K, et al. Acute demyelinating events following vaccines: a case-centered analysis. Clin Infect Dis. 2016;63(11):1456-1462.
25. Agmon-Levin N, Kivity S, Szyper-Kravitz M, Shoenfeld Y. Transverse myelitis and vaccines: a multi-analysis. Lupus. 2009;18(13):1198-1204.

26. Ropper AH, Poskanzer DC. The prognosis of acute and subacute transverse myelopathy based on early signs and symptoms. Ann Neurol. 1978;4(1):51-59.

27. Li R, Qiu W, Lu Z, et al. Acute transverse myelitis in demyelinating diseases among the Chinese. J Neurol. 2011;258(12):2206-2213.

28. Sepúlveda M, Blanco Y, Rovira A, et al. Analysis of prognostic factors associated with longitudinally extensive transverse myelitis. Mult Scler. 2013;19(6):742-748.

29. Chaves M, Rojas JI, Patrucco L, Cristiano E. Acute transverse myelitis in Buenos Aires, Argentina. A retrospective cohort study of 8 years follow up [in Spanish]. Neurologia. 2012;27(6):348-353.

30. Weinshenker BG, O'Brien PC, Petterson TM, et al. A randomized trial of plasma exchange in acute central nervous system inflammatory demyelinating disease. Ann Neurol. 1999;46(6):878-886.

31. Kleiter I, Gahlen A, Borisow N, et al. Neuromyelitis optica: evaluation of 871 attacks and 1,153 treatment courses. Ann Neurol. 2016;79(2):206-216.

32. Bonnan M, Valentino R, Debeugny S, et al. Short delay to initiate plasma exchange is the strongest predictor of outcome in severe attacks of NMO spectrum disorders. J Neurol Neurosurg Psychiatry. 2018;89(4):346-351.

33. Borowsky SJ, Cowper DC. Dual use of VA and non-VA primary care. J Gen Intern Med. $1999 ; 14(5): 274-280$.

34. Agha Z, Lofgren RP, VanRuiswyk JV, Layde PM. Are patients at Veterans Affairs medical centers sicker? A comparative analysis of health status and medical resource use. Arch Intern Med. 2000;160(21):3252-3257. 


\title{
Neurology \\ Neuroimmunology \& Neuroinflammation
}

\author{
Modern Look at Transverse Myelitis and Inflammatory Myelopathy: Epidemiology of \\ the National Veterans Health Administration Population \\ Justin R. Abbatemarco, Jonathan R. Galli, Michael L. Sweeney, et al. \\ Neurol Neuroimmunol Neuroinflamm 2021;8; \\ DOI 10.1212/NXI.0000000000001071
}

This information is current as of August 31, 2021

\section{Updated Information \& Services}

References

Subspecialty Collections

Permissions \& Licensing

Reprints including high resolution figures, can be found at: http://nn.neurology.org/content/8/6/e1071.full.html

This article cites 34 articles, 1 of which you can access for free at: http://nn.neurology.org/content/8/6/e1071.full.html\#\#ref-list-1

This article, along with others on similar topics, appears in the following collection(s):

All Demyelinating disease (CNS)

http://nn.neurology.org//cgi/collection/all_demyelinating_disease_cns Multiple sclerosis

http://nn.neurology.org//cgi/collection/multiple_sclerosis

Transverse myelitis

http://nn.neurology.org//cgi/collection/transverse_myelitis

Transverse myelitis

http://nn.neurology.org//cgi/collection/transverse_myelitis

Information about reproducing this article in parts (figures,tables) or in its entirety can be found online at:

http://nn.neurology.org/misc/about.xhtml\#permissions

Information about ordering reprints can be found online:

http://nn.neurology.org/misc/addir.xhtml\#reprintsus

Neurol Neuroimmunol Neuroinflamm is an official journal of the American Academy of Neurology.

Published since April 2014, it is an open-access, online-only, continuous publication journal. Copyright

Copyright $\left({ }^{\circ} 2021\right.$ The Author(s). Published by Wolters Kluwer Health, Inc. on behalf of the American

Academy of Neurology.. All rights reserved. Online ISSN: 2332-7812.

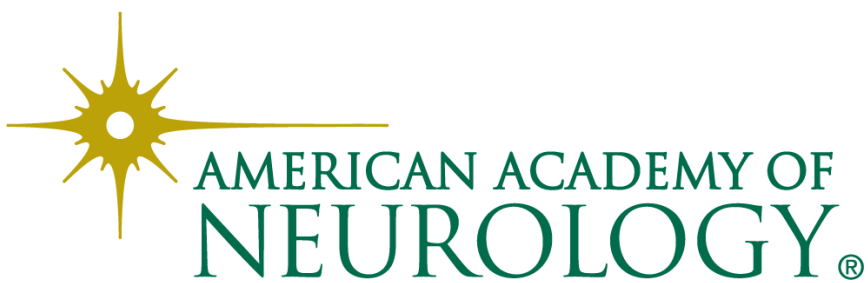

